\title{
Recortando a notícia: um olhar sobre os telejornais da record
}

\author{
Jaqueline Esther SCHIAVONI (UNESP)
}

RESUMO: A pesquisa realizada utiliza a semiótica francesa como o instrumento de análise de três telejornais produzidos pela Rede Record de Televisão: "Cidade Alerta", "Jornal da Record" e "Edição de Notícias", veiculados às 17h30, 21h00 e 00h00, respectivamente. As análises devem evidenciar as estratégias de persuasão utilizadas por cada telejornal para conquistar a adesão de seus respectivos enunciatários.

PALAVRAS-CHAVE: telejornal; enunciador; enunciatário; contrato

\begin{abstract}
The carried through research uses the French semiotics as the instrument of analysis of three television news produced by Rede Record de Televisão: "Cidade Alerta"; "Jornal da Record" e "Edição de Notícias", propagated at 5:30 pm, 9:00 pm and midnight, respectively. The analyses must evidence the strategies of persuasion used by each TV news to conquer the adhesion of its respective televiewers.
\end{abstract}

KEYWORDS: Tv news; subjects; figures 


\section{Introdução}

Desvendar estratégias de persuasão. Esse é o objetivo proposto no trabalho de pesquisa em desenvolvimento intitulado "telejornal: a informação recortada", a partir do qual foi possível a elaboração deste artigo. Assim, utilizamos a semiótica francesa como método para investigar a produção de sentido nos telejornais selecionados.

Os dados de audiência de cada telejornal por classe social, fornecidos pelo Instituto Brasileiro de Opinião Pública e Estatística (IBOPE), revelaram que as classes D e E são as que mais assistem ao "Cidade Alerta", enquanto que o "Jornal da Record" e o "Edição de Notícias" são mais assistidos pelas classes A e B. Por meio desses dados, procuramos estabelecer o público-alvo preferencial de cada telejornal.

As análises desenvolvidas se ocuparam em colocar em evidência os métodos utilizados pelos telejornais para conquistar a adesão de seus respectivos enunciatários e, assim, garantir pontos no IBOPE. Os resultados obtidos na pesquisa apontam elementos de produção que vão desde o projeto editorial dos telejornais ao uso de determinados planos e ângulos de filmagem. Neste artigo, entretanto, trabalharemos apenas com os três níveis do percurso gerativo do sentido.

A seguir se encontram dados relativos às editorias que cada telejornal privilegia e o tempo de duração de cada programa, uma vez que esses aspectos contribuem para a formação de uma identidade jornalística.

\section{Projeto editorial: uma questão de identidade}

Figura $1 *$

\begin{tabular}{|l|c|l|l|c|c|l|}
\hline EDITORIAS & $\begin{array}{l}\text { CIDADE } \\
\text { ALERTA }\end{array}$ & $\%$ & $\begin{array}{l}\text { JORNAL } \\
\text { DA } \\
\text { RECORD }\end{array}$ & $\%$ & $\begin{array}{l}\text { EDIÇÃO } \\
\text { DE } \\
\text { NOTÍCIAS }\end{array}$ & $\%$ \\
\hline Cotidiano & 21 & $95 \%$ & 4 & $26 \%$ & 4 & $22 \%$ \\
\hline Política & 1 & $4,5 \%$ & 3 & $20 \%$ & 2 & $11 \%$ \\
\hline Economia & - & - & 6 & $40 \%$ & 4 & $22 \%$ \\
\hline Internacional & - & - & 1 & $6,6 \%$ & 6 & $33 \%$ \\
\hline Esporte & - & - & 1 & $6,6 \%$ & 2 & $22 \%$ \\
\hline $\begin{array}{l}\text { Total de } \\
\text { Matérias }\end{array}$ & 22 & - & 15 & - & 18 & - \\
\hline $\begin{array}{l}\text { Duração do } \\
\text { programa }\end{array}$ & $2 \mathrm{~h} 10 \mathrm{~min}$ & & $0 \mathrm{~h} 45 \mathrm{~min}$ & & $0 \mathrm{~h} 28 \mathrm{~min}$ & \\
\hline
\end{tabular}

\section{$* 13 / 04 / 2004$}

Enquanto os telejornais "Jornal da Record" e "Edição de Notícias" atuam sob o slogan "as notícias mais importantes do Brasil e do mundo", privilegiando, de fato, respectivamente as notícias nacionais (economia) e internacionais, o "Cidade Alerta" mostra-se também em sintonia com sua proposta editorial conforme o slogan 
"jornalismo ágil e atual" de um "telejornal popular que investe em prestação de serviços, denúncia e investigação, sempre com o objetivo de mostrar os problemas da população e participar da comunidade", cedendo $95 \%$ de seu espaço para notícias cotidianas.

A própria apresentação dos telejornais (cerca de 17 linhas para o "Cidade Alerta", 9 para o "Jornal da Record" e 3 para o "Edição de Notícias) no site da emissora parece reproduzir o tempo de veiculação de cada programa, mas esse não é o aspecto mais significativo dessa apresentação. Afirmando compromisso com a imparcialidade, os telejornais contam com equipes independentes para suas produções jornalísticas, o que contribui para alcançar o objetivo editorial (enfoques) de cada programa. As edições regionais do "Cidade Alerta" confirmam seu caráter popular/comunitário, ao passo que a preocupação do "Jornal da Record" em manter uma comentarista especializada para os assuntos relacionados com Economia também lhe confere uma condição particularizada, voltada para os assuntos nacionais, com o objetivo de não apenas informar seu enunciatário, mas de contextualizá-lo efetivamente. Enquanto isso, o "Edição de Notícias" concentra-se em adiantar as notícias do dia seguinte ao seu telespectador, privilegiando os acontecimentos internacionais, utilizando até mesmo a internet, como objeto de busca para as manchetes de jornais impressos de outros países, na realização do programa.

\section{Uma análise semiótica}

Para analisar os recursos que os telejornais escolhidos utilizam para seduzir e persuadir seus respectivos enunciatários, selecionamos três notícias - corpus como um todo do trabalho de pesquisa de iniciação científica - no período de 12 a 17 de Abril de 2004, que figuraram nos três telejornais. Neste artigo, entretanto, trabalharemos apenas a notícia "Homem põe fogo no corpo em Brasília" (transcrição em anexo).

\subsection{Telejornal: "Cidade Alerta"}

Depois de ler a transcrição, observamos que essa notícia no jornal "Cidade Alerta” tem EXCLUSÃO SOCIAL (disfórico) x INCLUSÃO SOCIAL (eufórico) como oposição fundamental. A trajetória de José Antônio é a de um sujeito que se encontra em exclusão e atua objetivando a sua inclusão social, conforme afirma o apresentador Marcelo Resende: "O homem que foi dizer ao presidente da República, 'presidente, eu quero um pouco de dignidade, ".

No programa narrativo abaixo, o apresentador afirma que o sujeito José Antônio coloca um cartaz em frente ao palácio do planalto em Brasília para conseguir falar com o presidente Lula, conforme trecho da matéria:

\section{$\mathrm{PN} 1: \mathrm{F}[\mathrm{S} 1 \rightarrow(\mathrm{S} 2 \cap \mathrm{Ov})]$}

"Na frente do palácio do planalto ele coloca um cartaz: quero falar com o presidente Lula, sou um desempregado" 
Desse modo, temos nesse programa narrativo um sujeito reflexivo $(\mathrm{S} 1=\mathrm{S} 2=$ José Antônio - impulsionado pela situação de marginalidade: "sou um desempregado") que pretende entrar em conjunção $(\cap)$ com seu objeto valor $(\mathrm{Ov})$, ou seja, falar com o presidente Lula. A transformação $(\rightarrow)$ por parte do sujeito é colocar um cartaz em frente ao palácio do planalto (PN realizado), e a função $(\mathrm{F})$ é de privação.

Ao colocar o cartaz, José Antônio pretende persuadir o presidente Lula a ajudá-lo, como mostra o trecho da reportagem:

\section{PN 2: $\mathrm{F}[\mathrm{S} 3 \rightarrow(\mathrm{S} 2 \cap \mathrm{Ov})$}

"Estou pedindo meu direito de cidadão"

No programa narrativo (não realizado) acima o sujeito do fazer (S3) é o presidente Lula; o sujeito de estado (S2) é o José Antônio; o objeto valor (Ov) é a dignidade, a inclusão social; a função (F) é de privação.

Ao recorrer ao presidente, José Antônio reconhece na figura de Lula um actante adjuvante, que pode ajudá-lo, pois ele julga que Lula possui o poder-fazer (o presidente pode tudo na visão dos mais humildes), modalidade necessária à realização do fazer transformador, o qual realmente pode permitir a José Antônio obter seu objeto valor: a cidadania, a dignidade (emprego). Para isso, José Antônio tenta persuadir (por meio do cartaz) o presidente a querer-fazer e/ou dever-fazer algo em seu favor.

Tendo falhado o primeiro programa narrativo e não se realizado o segundo, a ação transformadora de José Antônio de colocar fogo no próprio corpo, renunciando à sua integridade física ao cometer um ato de alta imolação, é interpretada como "protesto", conforme julga Marcelo Resende, principalmente pele fato de se tratar de um ato extremo, conforme as palavras do apresentador: "É que pra ele já não dava mais como gritar, pra ele resistir. Só restou um gesto, e o gesto foi tacar fogo no corpo"

$\mathrm{PN}$ 3: $\mathrm{F}[\mathrm{S} 1 \rightarrow(\mathrm{S} 2 \cap \mathrm{Ov})$

"Ele protestou”

Novamente temos um sujeito reflexivo ( $\mathrm{S} 1=\mathrm{S} 2=$ José Antônio) cujo objeto valor é protestar por não ter conseguido falar com o presidente; a transformação $(\rightarrow)$ do sujeito é colocar fogo no próprio corpo e a função (F) é de aquisição.

$\mathrm{O}$ "Cidade Alerta" trabalha essa notícia com a isotopia da marginalidade, tanto no sentido de transgressão, que a palavra possui, como no sentido de se estar à margem da sociedade. Isso pode ser comprovado nas figuras e seus respectivos temas: "documento roubado" (exclusão); "perseguido pela polícia" (transgressão); "desempregado" (pobreza); "tiraram meu direito de cidadania" (exclusão); "vou corrigir o português" (baixa escolaridade); "barraco de oitocentos reais" (pobreza); estou perdendo minha família (rejeição).

Entretanto, outras temáticas tais como corrupção, desespero, etc, também podem ser identificadas no decorrer da matéria. 


\subsubsection{Efeito de subjetividade}

Comandado por Marcelo Resende, o "Cidade Alerta" - telejornal que se autointitula popular - tem na linguagem de seu programa um dos pontos determinantes para seu prestígio e audiência. Seus "profissionais falam com o telespectador sem intermediários", conforme a apresentação do programa no site da Record. O resultado é um discurso coloquial recheado por marcar de subjetividade, tais como pronomes retos, oblíquos e pessoais.

Verifica-se também que nesta matéria, de modo específico, há apenas uma voz no discurso, a do apresentador Marcelo Resende, e neste caso isso significa que "o discurso citado está subordinado a enunciação do discurso citante" (FIORIN, 2001 p. 75).

\subsection{Telejornal: "Jornal da Record"}

A notícia "homem põe fogo no corpo em Brasília" é construída por um enunciador que situa o Sujeito José Antônio em conjunção com a insanidade mental, materializada nas figuras que descrevem sus atitudes: dar "explicações desencontradas" para o ato - conforme a reportagem - e por cometer um ato incomum de "alta imolação" - segundo o parecer de um policial. A sanidade, que possui caráter eufórico na reportagem ( e no senso comum), deve ser buscada por meio de um "atendimento psiquiátrico" - registrado na sonora que contém a avaliação de um médico.

O sujeito José Antônio coloca fogo no próprio corpo porque queria falar com o presidente Lula, conforme trechos da reportagem:

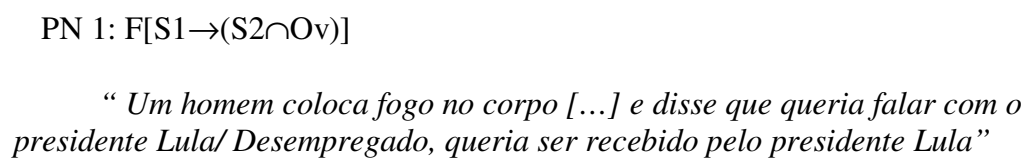

"Um homem coloca fogo no corpo [...] e disse que queria falar com o presidente Lula/ Desempregado, queria ser recebido pelo presidente Lula”

Nesse programa narrativo, temos um sujeito reflexivo $(\mathrm{S} 1=\mathrm{S} 2=$ José Antonio). O objeto valor (Ov) é falar com o presidente Lula; a transformação $(\rightarrow)$ é colocar fogo no corpo; a função (F) é de privação."

Enquanto o telejornal "Cidade Alerta" explicita o caráter de protesto do ato de José Antônio de "colocar fogo no corpo", o "Jornal da Record" considera a ação do sujeito como insana, pois suas explicações para o ato são "desencontradas".

Desse modo temos que:

$\mathrm{PN} 2: \mathrm{F}[\mathrm{S} 1 \rightarrow(\mathrm{S} 2 \cup \mathrm{Ov})]$

"o planalto não registrou, nem na guarita, nem na portaria, nenhuma tentativa de José Antônio para falar com o presidente” 
Novamente, o sujeito é reflexivo (S1 = S2 = José Antônio); o objeto valor $(\mathrm{Ov})$ é a sanidade mental; a transformação $(\rightarrow)$ é colocar fogo no próprio corpo e a função (F) é de privação.

A sanidade mental, tida como eufórica, constitui, segundo a reportagem e o senso comum, um objeto de valor que deve ser buscado, com mostra a sonora de um médico:

$$
\mathrm{PN} \text { 3: } \mathrm{F}[\mathrm{S} 1 \rightarrow(\mathrm{S} 2 \cap \mathrm{Ov})]
$$

"o atendimento psiquiátrico se faz necessário e vai ser feito em função do ato extremo"

O sujeito do fazer (S1) é o médico; o sujeito de estado (S2) é José Antônio; o objeto valor (Ov) é a sanidade mental; a transformação $(\rightarrow$ ) é o atendimento psiquiátrico; e a função (F) é de aquisição. A ação de devolver a sanidade ao sujeito José Antônio constitui um programa narrativo não realizado ainda.

O "Jornal da Record" trabalha nessa notícia a isotopia da insanidade mental, como mostram as figuras e seus respectivos temas: "deu explicações desencontradas para o ato" (insanidade); "o atendimento psiquiátrico se faz necessário e vai ser feito em função do ato extremo" (insanidade); "não tem registro de nenhuma tentativa para falar com o presidente" (dúvida); "dizia-se perseguido" (dúvida/dificuldade); "teria vendido o barraco" (dúvida/dificuldade).

Nos dois últimos exemplos, "dizia-se perseguido" e "teria vendido o barraco", a flexão dos verbos utilizados pelo repórter levanta a possibilidade da não veracidade da declarações de José Antônio,que termina por ser confirmada na abordagem da matéria que não dá a ele o benefício da dúvida instaurada pelo verbo nos dois casos, levantando, assim, a temática da insanidade.

Enquanto isso, com respeito a essa mesma matéria, o telejornal " Cidade Alerta" veicula na voz de Marcelo Resende as seguintes frases : "acabou perseguido pela polícia" e "ele vendeu a única coisa que ele tinha, o barraco de oitocentos reais", atribuindo verdade às ações declaradas por José Antônio - ou seja, considerando que as ações foram de fato realizadas - por meio das flexões verbais utilizadas.

\subsubsection{Polifonia e efeito de verdade}

$\mathrm{Na}$ matéria "Homem põe fogo no corpo em Brasília" várias vozes se apresentam no interior do discurso, tais como a de um delegado, um médico, uma testemunha ocular do fato e a do próprio José Antônio, além do repórter e do apresentador. Com diz Barros (2001 p. 59), "quando, no interior do texto, cede-se a palavra aos interlocutores, e discurso direto, constrói-se uma cena que serve de referente ao texto, cria-se a ilusão de situação 'real' de diálogo".

Essas vozes presentes na matéria dão veracidade ao fato, além de transmitirem ao telespectador a sensação de estar recebendo em sua casa a verdade absoluta, fruto da apresentação de vários pontos de vista, ou vozes, sobre o assunto. 
Para obter esse efeito de realidade/verdade, os telejornais contam ainda com a ancoragem $^{1}$, tanto pela apresentação de dados informativos verbais como por imagens que confirmam esses dados ou mesmo lhes acrescentem informações. Nessa matéria temos: A) ancoragem actancial: "José de Andrade de Souza, 30 anos"; B) ancoragem espacial: "em frente ao palácio do planalto", "vir à Brasília", " palácio do planalto", "praça dos Três Poderes", "hospital da asa norte, em Brasília"; e C) a própria ancoragem temporal, que encontra-se subentendida, pois trata-se da notícia do dia.

\subsection{Telejornal: "Edição de Notícias"}

A matéria "Homem põe fogo no corpo em Brasília" exibia no telejornal "Edição de Notícias" traz a oposição fundamenal MORTE X VIDA, segundo o enfoque do apresentador, que situa o sujeito José Antônio numa condição particular desfavorável, desassistida - "desempregado" - e que por isso parte em busca da ajuda, ou assistência, do presidente Lula. Nessa oposição, intencionamos o valor de socorro, auxílio que o verbo assistir pressupõe.

No programa narrativo abaixo, o apresentador afirma que o sujeito José Antônio coloca fogo no próprio corpo porque queria pedir ajuda ao presidente, conforme trecho da notícia:

$\mathrm{PN} 1: \mathrm{F}[\mathrm{S} 1 \rightarrow(\mathrm{S} 2 \cap \mathrm{Ov})$

“José Antônio queria pedir ajuda ao presidente Lula”

Nesse programa narrativo temos um sujeito reflexivo $(\mathrm{S} 1=\mathrm{S} 2=$ José Antônio);o objeto valor (Ov) é pedir ajuda ao presidente Lula; a transformação $(\rightarrow)$ é colocar fogo no próprio corpo; e a função $(\mathrm{F})$ é de privação

Nessa matéria o telejornal trabalha a notícia enfocando o pedido de José Antônio para falar com o presidente, ou seja, a isotopia do auxílio ou assistência, dada a condição do sujeito: desempregado. Isso revela-se nas figuras e nos seus respectivos temas: "um desempegado" (pobreza/auxílio); "José Antônio queria pedir ajuda ao presidente Lula" (auxílio).

Observa-se no telejornal "Edição de Notícias" o caráter predominantemente informativo dessa matéria, no qual o texto limita-se a responder basicamente as perguntas do Lead (o essencial da iformação): Quem? O que? Quando? Como? Onde? Por quê?

\section{Considerações finais}

As análises realizadas não esgotam as possibilidades de estudo do corpus. Elementos não-verbais (tais como vinheta de apresentação, passagem e finalização;

\footnotetext{
1 "Por ancoragem histórica compreende-se a disposição, no momento da instancia da figurativização do discurso, de um cconjunto de índices espaço-temporais [...] que visam a constituir o simulacro de um referente externo e produzir o efeito de sentido de realidade". (GREIMAS \& COURTES, p. 21)
} 
planos; cores; proxêmica; efeitos de sonoplastia; linguagem gestual e cenográfica; etc) também podem e devem ser considerados numa análise mais "exaustiva", já que se trata de um texto sincrético. Ainda assim, os aspectos abordados nesta pesquisa são capazes de confirmar, pelo prisma semiótico, o pressuposto do qual partimos: o da segmentação da informação.

Visto ser esse um "fenômeno" que atinge o fazer-jornalístico não apenas da Rede Record de Televisão, acreditamos que a pesquisa possa estabelecer modelos de análises para os telejornais de outras emissoras.

\section{REFERÊNCIAS BIBLIOLGRÁFICAS}

BARROS, D. L. P. de. Teoria Semiótica do Texto. São Paulo: Ática, 2001

FIORIN, J. L. As Astúcias da Enunciação.São Paulo, Ática, 2001 


\section{ANEXOS}

\section{Transcrições}

\section{CIDADE ALERTA NOTÍCIA: HOMEM PÕE FOGO NO PRÓPRIO CORPO EM BRASÍLIA}

Marcelo Resende: Um homem põe fogo em frente o Palácio do Planalto em Brasília. Põe pra mim, deixa eu ver a imagem. Olha aí, José Antônio Andrade, pode soltar, de Souza, de 30 anos. Ele se queimou. Cê vê que ele ta todo queimado. Foi socorrido por bombeiros, os para-médicos jogaram uma solução hidratante, por quê: O que que ele foi fazer: Por que ele se queimou: Porque ele queria ser recebido pelo presidente Lula. Como ele não conseguiu tcou fogo no próprio corpo. Ele colou um cartaz que você vai ver. Ele vendeu a única coisa que ele tinha, o barraco de 800 reais, porque ele já não tinha mais nada. Documento roubado, acabou perseguido pela polícia, desempregado. Esse talvez seja um retrato do Brasil, um retrato de um país, pode abrir o áudio dele, olha o rapaz sendo carregado, ele, volta aqui! Ele, ah! Que não dá pra voltar agora!! José Antônio, é uma imagem, não, não, não, volta lá na imagem, abre aqui, abre pra mim, porque na frente do Palácio do Planalto ele coloca um cartaz "quero falar com o presidente, sou um homem desempregado" e olhaí, parou, frisou pra mim, frisa por favor. "Senhor presidente", vou corrigir o português, cês me desculpem. "Vendi meu barraco por 800 reais para falar com você. Roubaram meus documentos, tiraram meu direito de cidadania, estão armando um monte de problema pra mim, estou perdendo minha família, estou pedindo meu direito de cidadão. José Antônio Andrade de Souza". O homem que se joga ali no chão. O homem que foi dizer ao presidente da República "presidente, eu quero um pouco d dignidade". Dá a imagem pra mim, "eu quero um pouco de dignidade, presidente Luís Inácio Lula da Silva”. São 10 milhões de desempregados, pega-se o dinheiro público e coloca-se em todos os lugares desse país, todos, o dinheiro público serve pra qualquer coisa, mas o dinheiro que deveia ir pra população ninguém sabe pra onde vai. Só não vai pra ajudar um rapaz como esse, e outros milhares, milhões de José Antônio. Esse protestou. É um erro? É. O que ele fez ele não deveria fazer. Não é isso que vai resolver a questão, ao contrário, ele só trouxe mais problema, mas é que às vezes, pra ele já não dava mais como gritar, pra ele resistir. Só restou um gesto, e o gesto foi tacar fogo no próprio corpo. Eu quero saber onde, até onde nós vamos chegar, qual é o limite, a capacidade de resistência. Porque dinheiro tem pra tudo, tem até pra pagar a dívida dos outros...

\section{JORNAL DA RECORD}

Boris Casoy: Um homem coloca fogo no corpo em frente o Palácio do Planalto. José Antônio Andrade de Souza estava há 3 dias em Brasília e disse que queria falar com o presidente Lula.

Reportagem: Um pedido de socorro. No cartaz colocado em frente ao Palácio do Planalto José Antônio Andrade de Souza, 30 anos, dizia-se perseguido Ele teria vendido 
o barraco onde morava para vir à Brasília. Desempregado, queria ser recebido pelo presidente Lula. Deu explicações desencontradas para o ato.

José Antônio: O policial me torturou, me espancou, desde os 17 anos eu to acabado, to um cara acabado, entendeu? Onde eu vou eu sou perseguido. Eu já tentei me suicidar, minha não deixou.

Reportagem: O Palácio do Planalto não registrou, nem na guarita, nem na portaria, nenhuma tentativa de José Antônio para falar com o presidente. A polícia disse que José Antônio nasceu em Minas Gerais e chegou à Brasília n domingo passado.

Polícia: Nesses 24 anos de polícia que eu tenho, foi a primeira vez que eu vi um caso desse de alta imolação.

Reportagem: Ismael Fernandez estava na praça dos Tês Poderes e viu quando José Antônio colocou fogo no corpo.

Ismael Fernandez: Ele saiu, pegou uma lata de álcool, jogou no próprio corpo, riscou um fósfor e pegou fogo, né? Aí ele veio pedindo socorro, né? Falou: "me ajuda, me ajuda". O propósito era apagar o fogo ali na hora, que ele rolasse no chão.

Reportagem: José Antônio foi internado aqui no hospital da asa norte, em Brasília, especializado em queimados. Ele sofreu queimaduras de $1^{\circ}$ e $3^{\circ}$ graus em $85 \%$ do corpo e está cedado. Embora estável, os médicos consideram o quadro bastante grave.

Médico: Essa é uma internação bastante longa que vai emfunção do tempo, da extensão da queimadura. $\mathrm{O}$ atendimento psiquiátrico se faz necessário e vai ser feito em função do ato extremo.

\section{EDIÇÃO DE NOTÍCIAS}

Paulo Henrique: Um desempregado botou fogo no próprio corpo na praça do Três Poderes, em Brasília. José Antônio de Andrade, de 30 anos, se queimou nos braços, costas e pernas. Os bombeiros levaram o rapaz para o hospital. O estado dele é grave. José Antônio queria pedir ajuda ao presidente Lula.

\section{Como citar este artigo:}

SCHIAVONI, Jaqueline Esther. Recortando a notícia: um olhar sobre os telejornais da Record. Estudos Semióticos, Número 2, São Paulo, 2006. Disponível em <www.fflch.usp.br/dl/semiotica/es>. Acesso em "dia/mês/ano". 